\title{
LA MEDIDA DE INTERVENCIÓN TELEFÓNICA
}

\section{THE TELEPHONE INTERVENTION MEASURE}

\author{
Edwin Duartes D. \\ Profesor \\ Universidad Autónoma de Centro América \\ duartes25@hotmail.com \\ Costa Rica
}

\section{SUMARIO}

- Introducción

- Concepto. Intervención y observación telefónica

- Naturaleza jurídica

- Régimen constitucional

- Régimen legal

- Autoridad competente

- Requisitos

- Los descubrimientos casuales

- Límites

- Identificación de la voz grabada

- La intervención entre presentes

- El valor probatorio de las escuchas telefónicas en el proceso penal

- Conclusiones

\section{RESUMEN}

El artículo contiene un análisis doctrinal, jurisprudencial y legal de las intervenciones telefónicas en delitos de importante gravedad, que tengan como finalidad el esclarecimiento de estos delitos. Esta intervención debe ser ordenada y controlada por un juez y protegida por una resolución motivada. El contexto jurídico gira alrededor de lo que existe en Costa Rica en este tema invocando, en algunos casos, jurisprudencia comparada. En el trabajo se ofrece una versión documentada de las técnicas de intervención, las limitaciones legales existentes en relación con sus alcances, cuáles son las esferas efectivas de esta figura y cuál es su valor probatorio en el sistema procesal vigente.

\begin{abstract}
ABTRACT
The article contains a doctrinal, jurisprudential and legal analysis of the subject of telephone interventions in crimes of serious gravity, whose purpose is to clarify these crimes. This intervention must be ordered and controlled by a judge, protected by a reasoned resolution. The legal context revolves around what exists in Costa Rica in this area, invoking, in some cases, comparative jurisprudence. The paper offers a documented version of the intervention techniques, the existing legal limitations in relation to their scope and, what are the effective spheres of this figure and what their probative value in the current procedural system.
\end{abstract}

\section{PALABRAS CLAVE}

Intervención telefónica, delitos graves, secreto de comunicaciones, orden judicial, motivación de la orden, proporcionalidad, necesidad

\section{KEYWORDS}

Telephone intervention, serious crimes, communications secret, court order, order motivation, proportionality, necessity

\section{INTRODUCCIÓN}

Los ciudadanos tienen derecho al secreto de sus comunicaciones. Lo que implica necesariamente que pueden comunicarse por teléfono, chat, cartas, correos electrónicos, etcétera.

Por medio de la transmisión oral o escrita, las personas expresan sus sentimientos y sus pensamientos. 
Pero estas prerrogativas y garantías a no ser lesionado el derecho a la libertad de expresión y comunicación no son absolutas. Precisamente, el guarismo 32 de la Convención Americana de Derechos Humanos impone ciertos límites en resguardo al derecho de la colectividad.

Es en el campo del derecho procesal penal donde de ordinario se imponen limitaciones a los derechos mencionados. Cuando exista una investigación en curso, es posible en aras de resguardar el derecho de la comunidad y del Estado en general, lesionar legítimamente libertades públicas.

En la sustanciación de un proceso investigativo por delito — con los recaudos legales-, es posible intervenir los teléfonos, imponerse del contenido de las cartas, grabar las comunicaciones entre presentes, etc.

Como se trata de un derecho fundamental, se ha confiado que sea el órgano jurisdiccional, regido por criterios de imparcialidad e independencia, que ordene, previo pedimento del actor penal, las medidas limitativas.

Intervenir una conversación telefónica es posible. Un juez puede imponerse de las llamadas sin que los interlocutores siquiera sospechen de que están siendo escuchados y grabados. Por medio de sofisticados aparatos de grabación y transmisión, también es posible escuchar la conversación entre dos personas presentes. En algunos casos, la investigación es más invasiva que en otros. Por ejemplo, la medida de intervención telefónica con respecto al secuestro de la correspondencia. La primera con respecto a la intervención entre presentes.

Objeto de esta exposición es analizar y valorar la técnica de investigación denominada «medida de intervención telefónica», sus limitaciones, requisitos, alcances, efectividad, valor probatorio.

\section{CONCEPTO. INTERVENCIÓN Y OBSERVACIÓN TELEFÓNICA}

Suelen escindirse dos circunstancias: a) la llamada escucha propiamente dicha; y, b) la observación telefónica.

Por intervención telefónica "...puede entenderse todo acto de investigación, limitativdel derecho fundamental al secreto de las comunicaciones, por el que el Juez... en relación con el hecho punible de especial gravedad y en el curso de un procedimiento especial, decide, mediante auto especialmente motivado, que por la policía judicial se proceda al registro de llamadas y/o a efectuar la grabación magnetofónica de las conversaciones telefónicas del imputado durante el tiempo imprescindible para poder preconstituir la prueba del hecho punible y la participación de su autor». (Gimeno, 1997)

La medida de intervención telefónica, tal y como sostiene la jurisprudencia constitucional costarricense, tiene dos vertientes: a) la observación telefónica, que es el procedimiento mediante el cual se aprecian los destinos de las llamadas, su duración; y, b) la escucha propiamente dicha, que es la imposición por parte de las autoridades del contenido de las comunicaciones orales. (Sala Constitucional 3195 y 4454,1995$)$

López Barja señala coincidentemente que: «... la intervención supone apoderarse del contenido de las conversaciones telefónicas, poder llegar a conocerlas. Por su parte el término observación ha de reducirse a poder tomar conocimiento del destino de la comunicación, la identidad subjetiva del receptor de la comunicación, al menos del titular, pero no permite el conocimiento del contenido, que debe permanecer secreto».

Tomás López-Fragoso Álvarez (1991) en forma amplia - sostiene que: «...López Barja se pronuncia en sentido afirmativo, al considerar, ...la "intervención" en el sentido de "apoderarse del contenido de lo comunicado", mientras que... con la expresión "observación" se refiere exclusivamente al recuento - comptage o pen register-, o sea, aquella actividad técnica que consiste en el empleo de un mecanismo que registra los números marcados, y así, en su caso, la identidad de los interlocutores, la hora o duración de la llamada, conjunto de actividades que el autor incluye en el más amplio término de "interceptación" "tomar conocimiento de la existencia, destino y / o contenido de una comunicación, aprehendiéndola de alguna manera».

Pascua (2003) separa entre la intervención propiamente dicha y la observación, aunque no utiliza esa nomenclatura: 
Las primeras son aquellas en las que la grabación del audio se realiza previo proceder a captar la señal telefónica del abonado a intervenir por intermedio de los organismos especializados al efecto, tomando posesión del número y la longitud para luego imponerse del contenido de las llamadas con o sin registro en los soportes respectivos, en las segundas, en cambio, se trata de la grabación de la conversación comunicación entre personas, en las cuales se procede a registrar, bien el mensaje telefónico, sin intervenir la línea, o bien la charla "in personam" mantenidas por ellas...

La medida se compone, pues, de dos elementos: laintervención y la observación. La intervención supone, como se explicó, apoderarse del contenido de las comunicaciones, en tanto el término observación se reduce a tomar conocimiento del destino de la comunicación y de la identidad subjetiva del receptor de la comunicación. En la legislación costarricense se utiliza intervención como sinónimo de interceptación, que es más comprensivo de cualquier forma de captura de la comunicación ajena; incluye la observación, tanto como la intervención. Ambas se rigen por criterios totalmente diferentes. Se ha dicho que, en cuanto a la primera, es una verdadera comunicación oral, mientras que la segunda es solamente un reporte de datos que no comporta lesión mayor al derecho a la intimidad personal.

En la jurisprudencia costarricense se ha sostenido que la observación telefónica la puede realizar la policía judicial o el fiscal, dentro de un proceso de investigación, sin impetrar el auxilio jurisdiccional. Se le llama sencillamente «rastreo de llamadas».

En la sentencia 132-1998, la Sala III de la CSJ costarricense comenta sobre la naturaleza jurídica del rastreo de llamadas, criterio que paulatinamente va mutando:

En este caso, entra a regir concomitantemente el numeral 1 de la Ley de Registro, Secuestro y Examen de Documentos privados, en donde expresamente se define como documento privado, entre otros a «cualquier otra forma de registrar información de carácter privado utilizados con carácter representativo o declarativo, para ilustrar o comprobar algo... Así, aunque como se dijo este procedimiento tenga relación directa con las comunicaciones y su inviolabilidad, la incidencia del mismo es obviamente distinta de la que se produce por el registro mismo de las llamadas, que implica imposición de su contenido. Se combina en el procedimiento de rastreo una incidencia en las comunicaciones telefónicas y la inviolabilidad de los documentos privados...

Con este argumento se parte de que el rastreo de llamadas u observación telefónica, por estar plasmada en documentos y tener íntima vinculación con el derecho a la intimidad, es un documento que debe ser secuestrado únicamente por orden de juez.

Como se indicó, dicha decisión varió, decantándose por lo innecesario de la orden jurisdiccional a efectos de secuestrar el listado o rastreo de llamadas de un teléfono determinado. ${ }^{1}$

Como se aprecia, el nivel de protección de los datos provenientes del registro de llamadas entrantes y salientes de un número telefónico no se compara con las escuchas telefónicas, autorizándose - por interpretación jurisprudencial - a la Policía Judicial y al Ministerio Público el secuestro respectivo.

1 «... en reiterados pronunciamientos y atendiendo lo que ha indicado la jurisprudencia constitucional, ha señalado que la solicitud y recopilación de los listados de llamadas realizadas y recibidas en un determinado derecho telefónico, no requiere de orden jurisdiccional. Así, en la resolución 2005-1172 de las 9:30 horas del 14 de octubre de 2005, en la que citó el voto de las instancia indicada, número 319595, de las 15:12 horas del 20 de junio de ese mismo año de aquella, se indicó: "Los recurrentes parten de la premisa equivocada de equiparar los rastreos o listados de llamadas telefónicas, con la intervención o conocimiento de las conversaciones ejecutadas por esa vía. En los primeros no se hace referencia alguna al contenido de las comunicaciones, sino que más bien la actividad se limita a identificar las llamadas entrantes y salientes de un número telefónico, consignándose los números hacia donde se dirigen las llamadas y los correspondientes de las recibidas, asi como su duración, fecha y hora. En el caso en particular, no se practicaron intervenciones telefónicas, sino únicamente rastreos de llamadas y en los términos aludidos, la prueba podia gestionarse, incluso sin orden jurisdiccional. Con motivo de un reclamo similar, ya tuvo ocasión de expresar esta Sala: “... Debe recalcarse, que la policia judicial estaba autorizada para solicitar la información cuestionada y que en todo caso se limitó a solicitar el rastreo telefónico, que tenía por objeto determinar de qué teléfonos procedian las llamadas y hacia cuáles se dirigían. Esta Sala ha señalado que la policia judicial puede realizar diligencias sin necesidad de contar con la participación del juez penal o del Ministerio Público... Esta actividad, conforme a los parámetros de legalidad que orientan su labor... le posibilitan actuar de oficio, o bien, de acuerdo con las circunstancias, ante la solicitud que le presenta la respectiva autoridad judicial.. (Arts. 286 del Código de Rito y 4 de la Ley Orgánica del Organismo de Investigación Judicial)...” (Fallo 871, de 9:20 horas del 12 de agosto de 2005)". (Sala III 095-07). 
En el derecho pretoriano es criterio reiterado. Basten algunos otros ejemplos: en las sentencias números 17097-07, 17935-07, la Sala Constitucional de Costa Rica reitera su criterio de que el rastreo de llamadas y la intervención telefónica son figuras diferentes; $\mathrm{y}$, en tanto la última está protegida por el artículo $24 .^{\circ}$ de la Constitución Política y solo puede ser autorizada por juez competente en los casos que taxativamente prevé la ley respectiva, la primera no está sometida a dichas restricciones y no viola el contenido del citado artículo constitucional, por lo que bien puede ser ordenada por el Ministerio Público. Sobre el tema se citan los votos 9421-02, 2268-03.

Respecto al rastreo de llamadas de teléfonos asignados a funcionarios del Estado, sus instituciones o municipalidades, con el objeto de ejercer el control disciplinario, importante doctrina ha dicho que no comporta lesión al derecho a la intimidad. ${ }^{2}$

\section{NATURALEZA JURÍDICA}

La intervención telefónica afecta la «... vida privada de una persona, sea aquella esfera en la que "puede excluir a terceros... como derecho a ser dejado tranquilo”» (Hernández, 1990)

Es una medida coercitiva, limitativa de derechos fundamentales. Así, ha sido reconocido por la doctrina. ${ }^{3}$

La jurisprudencia penal costarricense ha dicho que la intervención telefónica es un:

"...acto de investigación que abarca todas las llamadas que se realicen desde el número intervenido, independientemente

2 "Ahora bien, habiamos delimitado el ámbito de esta consulta a los casos en que no se puede interceptar la comunicación telefónica; no se puede escuchar y tampoco se puede conservar de modo alguno, sino, únicamente, registrar el número o extensión del que se llama desde la DIS, el número llamado (dentro o fuera de esa oficina) y el tiempo de duración de ésta. Las dos primeras hipótesis no plantean problema, en tanto son llamadas internas de funcionarios públicos, efectuadas en horas de oficina y desde un teléfono propiedad pública, de manera que el simple registro escrito del tráfico de llamadas, identificadas por el número de terminal, y de la duración de éstas no constituye una invasión al ámbito de privacidad personal protegido por la Constitución". (Cfr. PGR CR, Dictamen C-225-95 de 26 de octubre de 1995).

3 "... constituye una medida coercitiva accesoria que tiende por lo general a la obtención de pruebas conforme lo que se transmite por medio de la palabra a distancia por esta vian. (Pascua, 2003). Cafferata Nores (1983) sostiene igualmente, que la intervención de las comunicaciones participa de las medidas coercitivas. Zamorano (2006) es del criterio que constituyen medidas coercitivas accesorias y que proporcionan información que es importante en la investigación penal. de quién realiza las llamadas, así como también con independencia de que el contenido incriminatorio de las conversaciones se haya producido por una llamada originada o por otra recibida en el número intervenido, de tal forma que cualquier elemento probatorio que de allí se derive -aún si con ello se incrimina a terceros, también involucrados en la actividad ilicita- puede utilizarse válidamente en la fundamentación del fallo...» (Sala Tercera, 1996).

Con sustento en las posturas doctrinarias, coincidimos en que la medida de intervención telefónica es un medio coercitivo por medio del cual las autoridades investigativas limitan el derecho fundamental a la intimidad y al secreto de las comunicaciones con el objetivo de profundizar las investigaciones en curso, siendo regida por criterios de proporcionalidad; respecto a la gravedad de los delitos en los que se ordena, especialidad; respecto a que la medida de intervención telefónica únicamente ha de servir para investigar los hechos por los cuales se dispuso la orden y de necesidad; es decir, solamente si no es posible conocer lo que se desea por otros medios, se utiliza la medida de intervención telefónica.

\section{RÉGIMEN CONSTITUCIONAL}

La Convención Americana de Derechos Humanos en el artículo 11.2 dispone «Nadie puede ser objeto de injerencias arbitrarias o abusivas en su vida privada, en la de su familia, en su domicilio o en su correspondencia ...». La Declaración Universal de Derechos Humanos, en el artículo 12. ${ }^{\circ}$, la redacción es idéntica. El Pacto Internacional de Derechos Civiles y Políticos, en el artículo 17. ${ }^{\circ}$, dispone que: «Nadie será objeto de injerencias arbitrarias o ilegales en su vida privada, su familia, su domicilio o su correspondencia...».

Las transcritas normas convencionales protegen de injerencias arbitrarias o abusivas, ergo, podemos considerar a contrario sensu que se reconoce la posibilidad de que se lleven a cabo intromisiones en el ámbito de intimidad que no sean arbitrarias por estar permitidas por ley, ni abusivas por ser desarrolladas dentro del marco que esta le señala.

En Costa Rica el artículo $24 .^{\circ}$ de la Constitución Política protege la libertad y el secreto de las 
comunicaciones orales y escritas, y se regula el procedimiento de limitación de dicho derecho mediante las leyes 7425 y 8754 .

\section{RÉGIMEN LEGAL}

En Costa Rica su regulación es taxativa, conforme lo dispone el artículo $9 .^{\circ}$ de la ley 7425. Además, el artículo 16. ${ }^{\circ}$ de la Ley Contra la Delincuencia Organizada (Ley 8754, 2009), amplía la posibilidad de intervención de las comunicaciones. ${ }^{4}$

\section{AUTORIDAD COMPETENTE}

En Costa Rica dicha potestad descansa en el juez penal del Procedimiento Preparatorio (277 del Código Procesal Penal y 9 de Ley 7425 y 16 Ley 8754). Igualmente, en España y Argentina (579, Ley de Enjuiciamiento Criminal de España y 236 del Código Procesal Penal de La Nación Argentina).

\section{REQUISITOS}

En un Estado Constitucional de Derecho, es preciso que las autoridades públicas sean transparentes y el principio de interdicción de la arbitrariedad exige que los actos y decisiones de quienes detentan la autoridad pública sean motivados. Es la mejor garantía para proscribir la arbitrariedad. La fundamentación de las decisiones garantiza que se ha actuado de modo racional, porque se extienden las razones capaces de justificar su actuación u omisión y

4 Artículo 16. Autorización para la intervención de las comunicaciones. Además de lo dispuesto en el artículo $9 .{ }^{\circ}$ de la Ley N. $^{\circ} 7425$, y la presente Ley, el juez podrá ordenar la intervención de las comunicaciones cuando involucre el esclarecimiento de los delitos siguientes: a) Secuestro extorsivo o toma de rehenes. b) Corrupción agravada. c) Explotación sexual en todas sus manifestaciones. d) Fabricación o producción de pornografia. e) Corrupción en el ejercicio de la función pública. f) Enriquecimiento ilícito. g) Casos de cohecho. h) Delitos patrimoniales cometidos en forma masiva, ya sea sucesiva o coetáneamente. i) Sustracciones bancarias via telemática. j) Tráfico ilicito de personas, trata de personas, tráfico de personas menores de edad y tráfico de personas menores de edad para adopción. $\mathrm{k}$ ) Tráfico de personas para comercializar sus órganos, tráfico, introducción, exportación, comercialización o extracción ilícita de sangre, fluidos, glándulas, órganos o tejidos humanos o de sus componentes derivados. 1) Homicidio calificado. m) Genocidio. n) Terrorismo o su financiamiento. $\tilde{\mathbf{n}}$ ) Delitos previstos en la Ley sobre estupefacientes, sustancias psicotrópicas, drogas de uso no autorizado. o) Legitimación de capitales que sean originados en actividades relacionadas con el narcotráfico, el terrorismo, el tráfico de órganos, el tráfico de personas o la explotación sexual, o en cualquier otro delito grave. p) Delitos de carácter internacional. q) Todos los demás delitos considerados graves según la legislación vigente. permite el ulterior control. La obligación de razonar las decisiones judiciales sirve como una forma social en el control del ejercicio del poder público. Por eso, se ha dicho en algún lugar que contra el peligro de la arbitrariedad no hay mejor antídoto que la exigencia de la fundamentación.

Tal es la postura de la doctrina y jurisprudencia comparada. González-Cuéllar Serrano (1990) advierte que:

...el deber de motivación de las resoluciones judiciales restrictivas de derechos fundamentales que pueden ser adoptadas en el proceso penal es un requisito extrínseco formal para la constitucionalidad de dichas medidas, desde una óptica de respeto por el principio de proporcionalidad... Además la fundamentación externa de las decisiones judiciales es necesaria para facilitar el control, por parte de los órganos jurisdiccionales superiores, de la corrección de la aplicación de las normas jurídicas realizada por los inferiores, mediante el conocimiento de los recursos...

La Sala Constitucional de la Corte Suprema de Justicia de Costa Rica ha establecido que el deber de motivación de las decisiones «... integra el debido proceso...» $(6694,1993)$.

\section{Causa probable o indicio de delito}

Como sostiene Ruiz Vadillo (1997): « $L a$ medida ha de ser excepcional y sólo será utilizable en función de la gravedad del hecho que se pretende investigar y, por supuesto, motivada... no bastan las sospechas o conjeturas. Es necesario algo más; el indicio, es decir, la sospecha especialmente fundada. ...». Ergo, «No es ni puede ser, por consiguiente, un indicio la simple manifestación policial si no va acompañada de algún otro dato o de algunos que permitan al juez valorar la racionalidad de su decisión en función del criterio de proporcionalidad». (Tribunal Supremo Español, 1992)

El Tribunal Constitucional Español, en calenda 1 de diciembre de 1989 , señaló lo que no es precisamente indicio de delito: 
...Así tendríamos la sospecha, que consistiría en la aprehensión o imaginación de una cosa por conjeturas fundadas en apariencias o visos de verdad, la conjetura, que sería el juicio que, con ciertas probabilidades de acierto, se forman de las cosas o acaecimientos por las señales que se ven u observan y, finalmente, el indicio, que es la acción o señal que da a conocer lo oculto, en virtud de las circunstancias, que concurren en un hecho, dándole carácter de verosimilitud.

La jurisprudencia penal costarricense ha indicado que:

Resulta inexacto designar a las intervenciones telefónicas como notitia criminis... dado que no es legal ni común que el Estado se dedique al escrutinio indiscriminado de líneas de comunicación privadas... la noticia del delito, en fase de investigación, es previa al pronunciamiento judicial de interceptar un medio privado, de lo contrario dicha intromisión sería ilegítima. (Sala lll 183, 2002)

Continuando con la misma dialéctica argumentativa, Juan Montero Aroca (1999) señala: «...que la motivación no es un requisito de forma, sino una garantía; no es una formalidad, ni un elemento de cortesía, sino condición constitucional necesaria para poder sacrificar un derecho fundamental». Constante, pues, ha sido la doctrina del Tribunal Supremo Español en que la motivación de las decisiones judiciales constituye una garantía; $\mathrm{y}$, ha reiterado (Sala $\left.2^{\mathrm{a}}, 1995\right)$ :

Tiene razón el recurrente en cuanto que tales resoluciones debieron ser más explícitas en sus argumentaciones sin limitarse a rellenar los espacios en blanco de sendos impresos que se utilizaron al respecto. El titular del órgano judicial... tiene el deber inexcusable, no sólo de examinar cuidadosamente las peticiones que al respecto le sean hechas por tales funcionarios o autoridades para ver si en el caso se encuentra o no justificada la concreta medida de limitación de derechos que se solicita, sino también de expresar en el correspondiente auto cuáles son las razones especificas que en cada supuesto sirven de fundamento a la correspondiente autorización judicial.
El Tribunal Constitucional en S. 181/1995 ha dicho que: «...la restricción del derecho fundamental debe adoptarse por resolución motivada, y ello se debe a la íntima relación existente entre la motivación judicial y las circunstancias fácticas que legitiman tal restricción...».

Debe converger, del mismo modo, la necesidad procesal de la medida. Es decir, no basta con la simple existencia de indicio de delito, es preciso además fundamentar este otro extremo. Esto, por el carácter excepcional de la medida de intervención telefónica, la autoridad debe expresar motivadamente por qué estima atendible la intervención, justipreciando los intereses en pugna y considerando alternativas menos gravosas. Es preciso, además, que en auto o decisión que acuerde la intervención de las comunicaciones indique el delito o delitos que se investigan. La especialidad, como advierte Montero Aroca (1999), ha llevado también a decretar la nulidad e ineficacia de la intervención telefónica decretada respecto de un delito, pretendiéndose luego utilizarla como medio de prueba en un proceso en el que se acusa de delito distinto.

\section{Proporcionalidad y excepcionalidad}

López Barja (1989) sostiene que la intervención telefónica debe limitarse a delitos graves, lo que es una exigencia del sistema constitucional del equilibrio de las libertades y derechos fundamentales. Ruiz Vadillo (1989) señala que la medida debe ser excepcional. No debe decretarse si existe otro medio menos traumático. Montañés (1999) señala que la exigencia de que el delito sea grave proviene de que el «... principio de proporcionalidad exige una relativa gravedad de la infracción perseguida o relevancia social del bien jurídico protegido...».

Analizando las disquisiciones doctrinarias hechas en torno al delito grave, debe concluirse que esta es una exigencia del principio de proporcionalidad, que por delito grave debe entenderse conforme lo señala el 2.b de la Convención de las Naciones Unidas contra la Delincuencia Organizada Transnacional, adoptada por la Asamblea General de las Naciones Unidas el 15 de noviembre de 2000, que dice: «Por delito grave se entenderá la conducta que constituya un delito punible con una privación de libertad de al menos cuatro años o con una pena más grave». 
En Costa Rica se ha definido - a efectos de tipificar la legitimación de capitales-, delito grave como «...la conducta que constituya un delito punible con una privación de libertad de cuatro años como mínimo, o una pena más grave» (Ley 8304). Y, existe una lista de los delitos en los cuales procede ordenar la intervención telefónica.

\section{Destinatario de la orden de intervención}

Se asume que, a quien se interviene el teléfono, es imputado. Pero imputado es aquella persona a la que se imputa algo. Pascua (2003) sostiene esta tesis:

\section{...la atribución del carácter de imputado deviene desde el primer momento que la persona es sindicada de cualquier forma como partícipe de un delito, trátese de actos preprocesales, como la denuncia policial o el mismo sumario policial, o bien procesales propiamente dichos con el pleno ejercicio ya de la pretensión punitiva en cabeza del Ministerio Fiscal, ya que en caso contrario de admitirse y tal calidad sólo a partir de los actos jurisdiccionales se estaría restringiendo ilegalmente el derecho de defensa.}

Nos apartamos de dicho criterio. Es eventual que al imputado se le intervengan las comunicaciones, pero no todo intervenido es imputado. Pues precisamente existen situaciones en que los medios de prueba no retratan claramente al sospechoso como autor presunto de las delincuencias investigadas; $y$, la intervención telefónica tiene como objetivo, en estos supuestos, de llegar a un grado de convencimiento que permita enjuiciar al intervenido, hasta ahora, sospechoso. Eso no quiere decir que se trata de medidas predelictuales, puesto que existe leve indicio de delito. Hasta este momento no podemos intimar al sospechoso, porque no hay en su contra solventes indicios; no es posible sujetarlo al proceso penal; es simplemente un sujeto bajo investigación, un sospechoso.

Ocurre con frecuencia que, dentro de los procedimientos que se adelantan, se aprehenden también las comunicaciones de otras personas que no fueron tenidas en cuenta al momento de la investigación; $y$, supuestos en los cuales, a raíz de la intervención telefónica, se descubren hechos distintos a los investigados.
Estas circunstancias fácticas tienen cabida, no solo cuando se interviene un teléfono de una residencia o negocio, sino incluso cuando se trata de un teléfono público. Para garantizar el secreto de las comunicaciones, en Costa Rica se ha dispuesto legal y jurisprudencialmente que sea el propio juez (Ley 7425 y 8754. Sentencias 4454 y 3195 , Sala Constitucional, 1995). Debe existir una audiencia oral, en la que con participación de las partes se escuchen las conversaciones grabadas. Esto para garantizar el principio de contradicción e inmediación de la prueba. En Costa Rica existe esa obligación por disposición del art. 18 de la ley 7425 .

En conclusión la intervención no siempre es al teléfono del sospechoso, sino de personas contra las que existen desvaídos indicios que permiten deducir una sospecha delictiva, como señala Pascua (2003), generalmente por apreciaciones o informes policiales, basados en operaciones de inteligencia, que en realidad no suelen ser más que aportes vagos e imprecisos. Esto es lo que Pascua llama -indebidamente a nuestro juicio-, escuchas telefónicas predelictivas $\mathrm{o}$ de prospección (exploraty search), pues la mayoría de intervenciones telefónicas tienen origen y sustento en tales supuestos. Advierte Pascua que tales medidas deben ser rechazadas, ya que mientras el sujeto pasivo no se encuentre sindicado como imputado, es inadmisible la intervención judicial de sus comunicaciones telefónicas solo en mérito a los abstractos aportes de la policía. En todo caso debe evitarse interceptar comunicaciones de quien no es imputado, por cuanto en un Estado de derecho no puede olvidarse el apotegma que indica que «es válido investigar hechos para determinar quiénes son los responsables; en vez resulta irrito proceder a la inversa y meterse con un particular para cerciorarse de que sí incurrió en algún episodio reprensible».

Ha de entenderse que el teléfono intervenido es desde el cual se hacen las llamadas sospechosas. Que puede ser utilizado por diversos sujetos, pero que pertenece al sospechoso; y debe identificarse plenamente su ubicación y relación con el sujeto intervenido. Señalaba Pascua (2003) que solamente deben intervenirse las llamadas del sospechoso y no indiscriminadamente, pues ello es contrario al principio de proporcionalidad. 
La jurisprudencia española (STS, Sala II) sostiene una tesis contraria, pues posibilita la captación de las manifestaciones verbales de todas las personas que se comuniquen con el sospechoso y a través del teléfono intervenido. ${ }^{5}$

En cuanto al teléfono público, como anticipamos, es legalmente procedente su intervención, pero con vigilancia monitoreada; de modo que no se haga una escucha indiscriminada, aunque siempre habrá riesgo de que se filtren algunas conversaciones de personas $y$ hechos no relacionados con la investigación; lo deseable es que sean mínimos. El Tribunal Supremo Español ha considerado la validez de una intervención de un teléfono público por ser el utilizado por el sujeto pasivo investigado, si existen indicios de actuación criminal para la mejor planificación y desarrollo de los fines delictivos del agente; y, en esa línea ha fallado en sentencia de 18/04/1994, admitiendo la intervención de un teléfono semipúblico de una discoteca. (Pascua, 2003)

Montero Aroca (1999) comulga con la tesis de que no existe óbice alguno para intervenir un teléfono público o de acceso a público, siempre y cuando se tomen medidas para salvaguardar el derecho al secreto de las comunicaciones de las personas que pudieran llamar de ese teléfono y que no son objeto de la medida. Igualmente, Rodríguez Lainz (2002) sostiene la posibilidad de intervención de un teléfono público con identificación expresa de los interlocutores objeto de investigación, lo que ha sido admitido por la jurisprudencia española en la sentencia del Tribunal Supremo 467/1998 de 03 de abril, la que validó una intervención en dicho sentido, en la que se borraron las grabaciones de personas no sometidas a investigación y de temas personales.

\footnotetext{
5 “... como vulnerado el artículo 579.3 de la LECrim., en cuanto a la posibilidad de intervención de comunicaciones telefónicas de personas que no sean el presunto delincuente, sino de aquellas de las que se sirvan para la realización de sus fines delictivos... el propio artículo procesal que se de sus fines delictivos... el propio artículo procesal que se
menciona permite que el Juez pueda acordar la observación de las comunicaciones telefónicas no sólo de las personas sobre las que existan indicios de responsabilidad criminal, sino también de las que se sirvan para la realización de sino tambien de las que se sirvan para la realizacion de sus fines delictivos" (cfr. sentencia de 18 de junio de 1992).
Ello es justamente lo sucedido, dado que la solicitud de autorización judicial para la intervención del teléfono de... lo fue en función de las investigaciones dirigidas a conocer las actividades de... conviviente con aquélla en el domicilio en el que se halla instalado el teléfono... Obvio resulta, y esa es la intención de la norma procesal invocada, la posibilidad de intervención de teléfono de persona no imputada, ni, en principio, objeto de sospecha de una intervención directa, cuando tal teléfono es el que utiliza o del que se sirve el sujeto sobre el que existen indicios de actuación criminal, para la mejor planificación y desarrollo de sus propósitos delictivos.
}

Somos del criterio de que, independientemente de quien llame y se comunique con el imputado, la interceptación de las conservaciones resulta legal. ${ }^{6}$

\section{LOS DESCUBRIMIENTOS CASUALES}

Otro aspecto que no se debe soslayar es el referente a las divergencias entre el delito y el sujeto investigado y los resultantes de la escucha telefónica, también conocido como descubrimientos casuales. Debe identificarse si se trata de un nuevo delito cometido por el sospechoso y que es conexo con el investigado; $\mathrm{o}$, si se trata de un hecho ajeno; si se descubre un sospechoso y no el originario; o, el delito atribuido a este nuevo sospechoso, no es el previsto en la medida.

Como señala Pascua (2003):

Debe distinguirse en primer lugar si se trata de un nuevo delito que habría sido cometido por le imputado y que guarda relación con el ya investigado, o si por el contrario es ajeno al mismo; o bien, si lo que se descubre es un nuevo participe en el delito investigado, o en un delito diferente vinculado al investigado pero en el cual el incriminado es otro individuo y finalmente si se trata de un delito ajeno a la medida $y$ atribuido también a un sujeto distinto del pasivo de la medida. Debe lamentarse que la ley no establezca solución para un descubrimiento objetivo o subjetivo diverso al propugnado por la medida...

Los supuestos de descubrimientos casuales pueden ser diversos. La jurisprudencia costarricense recoge las siguientes hipótesis:

...en doctrina, se han llamado «descubrimientos casuales», queserefieren precisamente al encuentro - a partir de la intervención - de diversas situaciones como serían: a) hechos delictivos del acusado distintos del que motivó la

6 La jurisprudencia costarricense ha indicado: "...La intervención telefónica, como acto de investigación que es, abarca todas las llamadas que se realicen desde el número intervenido, independientemente de quién realiza las llamadas, así como también con independencia de que el contenido incriminatorio de las conversaciones se haya producido por una llamada originada o por otra recibida en el número intervenido, de tal forma que cualquier elemento probatorio que de alli se derive - aún si con ello se incrimina a terceros, también involucrados en la actividad ilicita- puede utilizarse válidamente ..... (Sala Tercera de la Corte Suprema de Justicia Cf. Voto 821-F-96) 
intervención; b) hechos delictivos de un tercero no autor ni partícipe del delito investigado, pero relacionados con éste; c) hechos delictivos de un tercero pero sin relación alguna con el delito investigado; d) conocimientos provenientes de un tercero, pero relacionados con el hecho investigado; e) conocimientos que provienen de un tercero que se refieren a un hecho delictivo distinto del investigado. [...] (Sala Tercera 872, 2002)

La ley no dispone nada al respecto, es lo que se denomina «descubrimientos casuales». La solución en la doctrina Argentina es de comunicar a la autoridad el nuevo delito cometido por el sospechoso, pero si se trata de un hecho no vinculado y de un sujeto ajeno, estima que la intervención es ilegítima. (Pascua, 2003)

En la provincia de Córdoba la jurisprudencia ha sostenido que las escuchas telefónicas no pueden ser valoradas durante un proceso cuando fueron producto de una investigación direccionada a los imputados de otra causa, ya que se analizan, se estaría violando el principio de defensa en juicio, toda vez que al producirse dicha prueba, nada se sospechaba ni se investigaba en contra de aquellos imputados en el proceso en curso.

Comentando el mismo fallo, Montero Aroca (1999) dice:

...el Tribunal no necesitó llegar a cuestionarse las consecuencias jurídicas de lo que han llamado descubrimientos casuales. Enelprocesoiniciallaintervención telefónica fue acordada por el Juez francés en la investigación del asesinato del «caso Baron» y acabó descubriéndose, por medio de la intervención, que dos interlocutores no investigados, participaron en otro asesinato, el de la «causa La Garbe d Or». Declarada la violación del art. 8 del CEDH, porque la ley francesa no proporcionaba al imputado la protección adecuada contra los posibles abusos (calidad de la ley), el Tribunal no tuvo la necesidad de cuestionarse, y no lo hizo, el aspecto del descubrimiento de hechos casuales; adviértase que se trataba de que dos personas no investigadas mantienen una conversación sobre un delito distinto del investigado.
Gorgas (2004) indica que la justicia española falló en el siguiente sentido:

Debe recordarse la invalidezy consiguiente ineficacia probatoria de los datos fácticos acreditados por medio de una intervención de las comunicaciones cuando los mismos se pretenden hacer valer en una causa distinta y para unos delitos también distintos de aquellos cuya investigación se concedió la autorización judicial correspondiente, cuando, tras advertirse la existencia de indicios de otros posibles hechos delictivos distintos, no se haya instado y concedido la correspondiente autorización para ampliar el objeto de la investigación de los mismos.

Igualmente ha dicho que no son correctas las autorizaciones genéricas, ni tampoco sin la nueva y expresa autorización del juez. Es correcto mantener la intervención/observación cuando se descubre que el nuevo y presunto delito que se dibuja por la telefonía, es independiente del que fue objeto de la autorización genuina (Gorgas, 2004). En el mismo orden de ideas, la jurisprudencia ha indicado que no se puede renunciar a la notitia criminis incidentalmente descubierta en una intervención dirigida a otro fin, aunque precise una ampliación o nueva y específica autorización judicial, o el inicio de nuevas investigaciones. En Alemania se conocen los descubrimientos casuales como zufallsfunden, opinando la doctrina que debe iniciarse un nuevo procedimiento ante el anoticiamiento del hecho casual. (Montoya, 2001 y Gorgas, 2004)

Haciendo pues un inventario de la doctrina expuesta, es posible colegir el criterio dominante en todas ellas, de que los descubrimientos casuales en una intervención telefónica tienen el valor de notitia criminis y que ante su fortuito descubrimiento debe la autoridad ampliar la medida originaria mediante una decisión motivada u ordenar una nueva investigación paralela.

Gorgas (2004) construye su posición a partir de un parangón con la medida de registro domiciliario en el que también rige el principio de especialidad. Señala que los descubrimientos y secuestros casuales en el allanamiento son convalidados por la jurisprudencia argentina y española. Entiende que tal como ocurre en la prolífica jurisprudencia existente en materia de 
descubrimientos casuales en allanamientos, los argumentos dados en su apoyo son aplicables a la situación análoga en las intervenciones de las comunicaciones telefónicas. Advierte que no existe violación de las garantías constitucionales y pueden valorarse los datos obtenidos relacionados a nuevos hechos independientes del investigado, mediando los siguientes requisitos: a) legitimidad de la orden inicial (con observancia de las formalidades); b) desconocimiento previo de los hechos ajenos a la investigación que podrían descubrirse (buena fe de los funcionarios actuantes); c) autorización expresa o tácita del magistrado que dispuso la intervención para que sean escuchadas en otra investigación; d) anoticiamiento de las nuevas novedades a la autoridad judicial competente y el pedido de una intervención al juez si se quisiera seguir con la intervención.

La postura de Gorgas, en el supuesto costarricense, varía un poco. La jurisprudencia respeta el principio de especialidad. De modo que, aunque el hecho causal constituya delito de los que autorizan la intervención telefónica, el develamiento fortuito, solamente tiene el valor de notitia crimini; de modo que no es posible utilizar las escuchas como prueba de cargo. ${ }^{7}$ Esta postura de utilización de los descubrimientos casuales se articula perfectamente con lo resuelto por el Tribunal Europeo de Derechos Humanos en fallo de 06.09.1978, que fustigó las intervenciones explorativas y generales. Señaló que solamente es posible en forma fundada y específica; $y$, la sospecha de que un ciudadano está cometiendo delito autoriza al Estado a investigarlo, y a evitar que el asunto llegue a consecuencias ulteriores; sobre todo, en delitos como el tráfico de drogas, donde la prueba es de difícil obtención y se ha recurrido a métodos y técnicas elaboradas para la investigación.

Luego de analizadas cada una de las posturas, exponemos nuestro punto de vista. La medida de intervención telefónica, por ser una interferencia «grave» a los ámbitos de privacidad e intimidad; deben ser utilizadas

\footnotetext{
7 «... si bien no se podría eliminar el conocimiento obtenido a partir de esos descubrimientos casuales, también es lo cierto que ello no implica que ese conocimiento no pueda ser tomado en cuenta como "notitia criminis", de modo tal que, a partir de ese conocimiento fortuito, el juzgador podría iniciar una investigación independiente sobre ese nuevo hecho en la que no podría de ningún modo, incluir las intervenciones a partir de las cuales obtuvo esa noticia. [...]". (Sala Tercera Corte Suprema de Justicia Voto 2002-00872)
}

como ultima ratio cuando otras medidas menos gravosas no funcionen.

Eso significa, además, que solo debe adoptarse para la investigación de delitos especialmente graves. Para determinar ese criterio, debe partirse de una base objetiva, tal y como lo reseñáramos; es decir, aquellos delitos cuya escala penal sea igual o superior a los cuatro años de prisión. La decisión debe ser debidamente motivada, donde se expresen los indicios existentes, la vinculación de determinado sujeto con esos indicios y, sobre todo, la necesidad de la medida.

Los descubrimientos casuales deben tener el valor de notitia criminis. Es decir, la información obtenida de ella no debe servir de prueba en el otro proceso. De lo contrario se permitiría que la policía invente un supuesto delito grave y utilizaría esta medida coactiva para la investigación de delitos menos graves. Al momento de hacerse la trascripción de las conversaciones, debe concederse audiencia a la defensa para cumplir con el principio de bilateralidad, de modo que aquella pueda combatir la fidelidad entre lo escuchado y lo trascripto, así como el sentido de las palabras; porque hacerlo, cuando constituye una prueba preconstituida a espaldas de la defensa, vulnera el debido proceso.

\section{LÍMITES}

Nos mostramos partidarios por permitir la intromisión dentro del ámbito de reserva estudiada, pero siempre con la autorización y fiscalización expresa de un juez; autorización debidamente razonada y relacionada con el objeto de una investigación por un hecho delictivo grave; que afecte un bien jurídico importante. De modo tal que el investigador motu proprio, no podrá incursionar en la zona de reserva; $y$, tampoco, podrá ir más allá de lo expresamente autorizado.

Fernando Cruz (1989) sostiene que: «...las interceptaciones telefónicas o de cualquier comunicación privada del acusado, requieren límites definidos. Se trata de una grave invasión de la vida privada en la que el Estado no debe tener poderes irrestrictos; en este aspecto no resulta suficiente que la intervención la ordene una autoridad judicial y se requiere el cumplimiento de otros requisitos tal y como los contempla la legislación italiana». 
También, en lo que se refiere a la duración de la medida, se impone el principio de inocencia, que impide que los actos coactivos lleguen a extenderse más allá de lo estrictamente necesario. ${ }^{8}$

Por ello precisa esta forma de intervención estatal, se haga con respecto a delitos que asuman cierto carácter de gravedad que justifique la medida; además, conciliar la realidad delictiva con el respeto a los derechos fundamentales del imputado, de modo que no se extienda la intromisión estatal, fuera de lo estrictamente necesario.

Se considera una extensión de la intimidad, su intervención sigilosa debe restringirse a aquellos casos en que sea imprescindible para la investigación. Solo es admisible previa orden judicial y en relación con la comunicación del sospechoso, quedando excluida la posibilidad de interferir las de este con su defensor.

En este sentido, comulgamos con la tesis de que la orden sea dispuesta por un juez de la República, no comprometido con la investigación, para garantizar la imparcialidad. La solicitud de intervención debe ser escrita, motivada y la resolución que la conceda debe explicitar de modo indubitable el hecho que se pretende esclarecer, el propietario o propietarios del medio de comunicación a intervenir, o del destinatario de la comunicación y su vinculación con los hechos y el periodo durante el cual rige la medida ordenada, que podrá hacerse por lapsos de un mes que no puede exceder de tres meses, salvo en casos de extrema gravedad o dificultad.

No se desconoce con lo anterior la existencia de delitos organizados y muy complejos como el narcotráfico, terrorismo, homicidios calificados, donde los delincuentes utilizan claves de comunicación y que su descubrimiento por parte de la policía resulta difícil.

8 Maier (1989) explica que: "...el hecho de reconocer que el principio de inocencia no impide la regulación y aplicación de medidas de coerción durante el procedimiento - antes de la sentencia de condena firme que impone una pena-, según el texto de la ley fundamental o el sentido histórico-cultura de la garantía, no significa afirmar que la autorización para utilizar la fuerza pública durante el procedimiento, conculcando las facultades de las que gozan quienes intervienen en él, en especial, las del imputado, sea irrestricta o carezca de limites. [...] Este principio rector, que preside la razonabilidad de la regulación y de la aplicación de las medidas de coerción procesal puede sintetizarse expresando: Repugna al Estado de Derecho, previsto en nuestro estatuto fundamental, anticipar una pena al imputado, durante el procedimiento de persecución penal".
Las llamadas seleccionadas solo deben ser las relacionadas con el hecho investigado, debiendo el funcionario discriminarlas para no afectar la garantía de la intimidad. Pero no basta con que el mismo funcionario escuche la conversación y la transcriba, en la labor de selección de conversaciones y su documentación; debe existir participación de la defensa, pues se trata de la preconstitución de prueba de importancia toral para el proceso penal panameño y no debe privarse al ejercicio de la defensa técnica.

Tres meses, prorrogables por dos tantos iguales, para un máximo de nueve meses de intervención, es suficiente. Un periodo prolongado más allá, atenta contra el derecho a la privacidad y a la intimidad.

Ahora bien, se plantea una interrogante: ila duración de la intervención es respecto al teléfono o al investigado? Es harto conocido que los delincuentes dedicados al tráfico de drogas cambian constantemente de teléfonos o utilizan varios a la vez. Por lo que consideramos que el plazo de la medida es respecto al teléfono y no al investigado.

\section{IDENTIFICACIÓN DE LA VOZ GRABADA}

En Costa Rica no se tiene solución legal alguna al cuestionamiento que se presenta - no raras veces - a la autenticidad del registro de voz y su atribución a un sujeto determinado. Cuando se cuestiona el registro propiamente, y comprobada su falta de fidelidad, afecta sensiblemente la prueba, existiendo un quebranto a la cadena de suministros y conservación de la prueba que la torna ilegítima.

Pero cuando el cuestionamiento lo hace el mismo sospechoso o imputado, advirtiendo que no se trata de su voz, quedan - como señala Pascua (2003) —, algunas alternativas: a) verificación pericial; b) practicar un cuerpo de voces de diferentes individuos por las distintas personas que puedan reconocerla; c) simple reconocimiento de testigos; y, d) realizar cotejo de voces con el material indubitable. Sin embargo, nada obsta para que el juez, recurriendo a las reglas de la sana crítica, haga la valoración probatoria respectiva.

En Costa Rica es rara la utilización de los cuatro recursos citados, no se conoce tampoco 
su frecuencia, siendo utilizables las reglas de la sana crítica. En España el peritaje es realizado por la Sección de Acústica Forense, dependiente de los organismos policiales.

Es importante, además, que los organismos de investigación realicen una prueba de tenencia para identificar, en la medida de lo posible, a la persona que utiliza el teléfono; lo que unido a las referencias nominales, motes que hagan de los usuarios al conversar telefónicamente y lo característico de la voz, se conviertan en insumos suficientes a la hora de resolver las objeciones sobre si a quien se imputa es precisamente quien conversaba en la línea.

\section{LA INTERVENCIÓN ENTRE PRESENTES}

La intervención entre presentes trata de una intervención in personam, realizada por las autoridades investigativas para imponerse del contenido de sus comunicaciones orales y que se adopta en condiciones de estricta necesidad, pues se trata de una mayor vulneración al ámbito de la intimidad. Por ejemplo, el uso de micrófonos en habitaciones cerradas, casas de habitación, oficinas. La Sala Tercera costarricense decretó la ineficacia de escuchas obtenidas mediante un descuido de los habitantes de la casa de habitación, al dejar el teléfono mal colgado, lo que permitió que este funcionara como un verdadero micrófono capturando todas las manifestaciones verbales producidas. ${ }^{9}$

Esta técnica es excepcionalísima, ya que exige una verdadera invasión al ámbito de intimidad,

\footnotetext{
9 «... Efectivamente, observa esta Sala que durante las escuchas realizadas por la Jueza Penal, la misma incluyó conversaciones entre personas presentes en el domicilio, puesto que por error o descuido, alguien no cortó la llamada que habia ingresado al teléfono intervenido. Esta situación permitió que se grabaran, no las conversaciones realizadas por el aparato telefónico, sino un diálogo entre las personas que estaban en el domicilio... "En los mismos casos, dichos tribunales podrán autorizar la intervención de las comunicaciones entre los presentes, excepto lo dispuesto en el segundo párrafo del artículo 26 de la presente Ley; cuando se produzcan dentro de domicilios y recintos privados, la intervención solo podrá autorizarse si existen indicios suficientes de que se lleva a cabo una actividad existen indicios suficientes de que se lleva a cabo una actividad
delictiva". Resulta, en consecuencia, que la ley hace una distinción entre la intervención de comunicaciones por medio de telecomunicaciones fijas, móviles, inalámbricas y digitales, de la intervención de comunicaciones entre personas presentes. Esto último sería como utilizar micrófonos u otros medios para captar la comunicación. Si por una circunstancia casual o accidental, un teléfono no se cuelga adecuadamente, y por eso se graban conversaciones producidas en el ámbito de intimidad del domicilio, esta prueba no se puede equiparar a las escuchas telefónicas, y en consecuencia, el órgano jurisdiccional encargado de realizar la intervención, debe excluirlo". (Sala Tercera Corte Suprema de Justicia, voto 2005-00139).
}

pudiendo utilizarse durante una conversación, por medio de micrófonos que transmiten la señal a distancia o colocación de dispositivos auditivos en una casa de habitación o lugar cerrado; más grave aún resulta el uso de cámaras, que está proscrito por razones de proporcionalidad. Es decir, el uso de videocámaras en habitaciones excede los parámetros de lo razonable y puede dejar vacía la garantía de inviolabilidad del domicilio. La utilización de esta medida de investigación con prescindencia de la orden jurisdiccional hace que la conducta de los funcionarios constituya delito de captación indebida de manifestaciones verbales. Imponerse del contenido de las conversaciones telefónicas a distancia celebradas en una casa de habitación, por medio de sofisticados aparatos, constituye un allanamiento impropio; $y$, no es posible que mediante fraude de ley se trate de vulnerar garantías fundamentales a la intimidad e inviolabilidad del domicilio.

No despreciamos cuán útil es este medio de investigación en esta época donde los traficantes de drogas, terroristas y otros delincuentes se reúnen para tratar personalmente temas claves de los delitos; pero no puede perderse la perspectiva y convertir el proceso de autorización jurisdiccional en un proceso laxo, sin sujeción a las garantías y prerrogativas garantizadas constitucional y universalmente.

Debe entenderse que, para la procedencia de esta medida coercitiva, como de la intervención telefónica, precisa la concurrencia de suficientes indicios. Es decir, debe existir una causa probable que sea constatable objetivamente más allá de los simples informes confidenciales.

\section{EL VALOR PROBATORIO DE LAS ESCUCHAS TELEFÓNICAS EN EL PROCESO PENAL}

La prueba de las conversaciones es el propio instrumento donde ellas quedan grabadas. De permitirse que sean las transcripciones o los testimonios de quienes la escucharon, se corre el indeseable riesgo de la mediatización de la prueba; puesto que quienes han intervenido generalmente anotan solamente aquello que les impresionó y no necesariamente es fiel reflejo de lo que consta en la realidad. Esta ha sido la postura de la jurisprudencia penal 
costarricense: «...La prueba en el caso de las intervenciones telefónicas es lo registrado en los "casettes", esto es, las grabaciones y no las transcripciones, independientemente de que para efectos de analizar la prueba y sustentar el fallo se haga alusión a las transcripciones - que por lo dicho constituyen una forma práctica de tener siempre a mano lo grabado...». (Sala III, 1997)

Ahora bien, resta analizar el tema del valor probatorio que tienen las escuchas en el proceso penal. ¿Son prueba plena? ¿Es prueba indiciaria?

Es inocultable que en el proceso penal rige el principio de libertad probatoria; por eso, no puede pensarse en que el valor probatorio de las escuchas telefónicas pueda ser tasado. De momento, podría constituir, en ausencia de otros elementos, en mero indicio de criminalidad, tal y como lo ha sostenido la jurisprudencia costarricense. En un caso se señala: «...pues como prueba esencial solo se contó con el contenido de las escuchas, sin que se analizara ni valorara la eventual precisión, seriedad o veracidad de la información suministrada, ni tampoco el tema del efectivo recibo de dinero o ventaja patrimonial...». (Sala III, 2005).

\section{CONCLUSIONES}

El uso de las medidas de intervención telefónica, como técnica de investigación, debe reservarse a delitos especialmente graves y lo deseable, como en el caso costarricense, es que opere una lista taxativa de delitos en los que es admisible. Quebranta el principio de proporcionalidad, su uso para la investigación de delitos menores o faltas.

El juez es el único autorizado para ordenar la limitación del derecho fundamental de la intimidad y del secreto de las comunicaciones, pero a la par de ello, deben exigirse importantes recaudos: a) no debe actuar de oficio; b) debe dictarlo mediante decisión debidamente fundamentada pues, como se ha dicho, la motivación de las decisiones de los poderes públicos, en cuenta de la función de la administración de justicia, es la mejor garantía para proscribir la arbitrariedad. La fundamentación de las decisiones garantiza que se ha actuado de modo racional, porque se extienden las razones capaces de justificar su actuación u omisión y permite el ulterior control. Como señala Juan Montero Aroca (1999), la motivación no es un requisito de forma, sino una garantía; no es una formalidad ni un elemento de cortesía, sino condición constitucional necesaria para poder sacrificar el derecho fundamental. c) Deben imponerse límites temporales. Y, d) Debe existir un control judicial en la ejecución de la medida y no confiarla exclusivamente a los órganos de investigación, pues es preciso la protección de información no relacionada con la investigación; es decir, de la información estrictamente personal.

La utilización del recurso de intervención entre presentes debe ser regida por principios de ultima ratio, proporcionalidad y necesidad, solo cuando no sean eficaces otras formas de investigación, pues lo estimamos una invasión más profunda.

\section{REFERENCIAS BIBLIOGRÁFICAS}

Armijo, G. (1997). Garantías Constitucionales, prueba ilícita y la transición al nuevo proceso penal. San José, CR: Colegio de Abogados.

Barrios, B. (2000). Las operaciones encubiertas. Panamá: Ediciones Panamá Viejo.

Becerra, N. (1998). El Ministerio Público y los nuevos desafios de La Justicia Democrática. Bs. As.: Editorial Ad-Hoc.

Binder, A. (1993). Introducción al derecho procesal penal. Buenos Aires: Ac Hoc.

Cafferata, J. (1983). Medidas de coerción en el proceso penal. Buenos Aires: Ed. Lerner, p. 143

Cafferata, J. (1994). La prueba en el proceso penal. Buenos Aires: Depalma.

Cafferata, J. (2002). Escuchas telefónicas. Córdoba. En Temas de derecho procesal. Mediterránea.

Clariá, J. (1998). Tratado de derecho procesal penal. Buenos Aires: Ediar, Bs.

Cortés, R. (1998). La etapa preparatoria en el nuevo proceso penal. Costa Rica: Investigaciones Jurídicas S.A.

Creus, C. (1988). Derecho penal (Parte General). Buenos Aires: Astrea. 
Cruz, F. (1989). La Defensa Penal y la Independencia Judicial en el Estado de Derecho. San José, Costa Rica. Departamento de Capacitación Instituto Latinoamericano de Naciones Unidas para la Prevención del Delito y Tratamiento del Delincuente, Unidad Modular VI.

Chiesa, E. (1991). Derecho Procesal Penal de Puerto Rico y Estados Unidos. Colombia: Editorial Forum, Colombia.

Chinchilla, R. (2006). Ley sobre registro, secuestro y examen de documentos privados a intervención de las comunicaciones, Investigaciones Jurídicas, San José, Costa Rica. Investigaciones Jurídicas S.A.

Chirino, A. (1999). «Protección de datos y moderno proceso penal: aspectos constitucionales y legales». Costa Rica. Revista del Ministerio Público Fiscal N. ${ }^{\circ}$ 2., p. 85.

De la Rúa, F. (1989). «El imputado». Buenos Aires. Enciclopedia Jurídica Omeba (T. XV), Impo-Insa, Bibliográfica Omeba, Driskill, S.A. p. 248.

Ferrajoli, L. (1995). Derecho y Razón. Madrid, España: Editorial Trotta.

Gimeno, V. (1997). «Las intervenciones telefónicas en la jurisprudencia del TC y TS». Buenos Aires. En AAVV Derecho Procesal en Visperas del siglo XXI, Sociedad Anónima Editora, Comercial, Industrial y Financiera. p. 428

González, D. (1996). «El procedimiento preparatorio». Costa Rica. En Reflexiones sobre el Nuevo Proceso Penal. Colegio de Abogados. p. 142.

González, N. (1990). Proporcionalidad y derechos fundamentales en el proceso penal. Madrid: Edit. Colex.

Hairabedián, M. (2000). La filmación como prueba en el proceso penal. Córdoba, Editorial Mediterránea. p. 158.

Hairabedián, M. (2002). Novedades sobre la prueba judicial. Córdoba, Editorial Mediterránea.

Hairabedián, M. (2004). Cuestiones prácticas sobre la investigación penal. Argentina: Editorial Mediterránea.
Hernández, R. (1990). Las Libertades Públicas. San José, Costa Rica: Editorial Juricentro. p. 133.

López Barja. (1989). Las escuchas telefónicas y la prueba ilegalmente obtenida. Madrid: Editorial Akal. pp. 194-150.

López, T. (1991). Las intervenciones telefónicas y el derecho a la intimidad. Madrid: Edit. Colex, Española y Leyes S.A.

Llobeth, J. (1988). Proceso penal comentado. San José: Universidad para la Cooperación Internacional.

Maier, J. (1989). Derecho procesal penal argentino. Buenos Aires: Hammurabi, pp. 276277.

Malatesta, N. (1988). Lógica de las pruebas en materia criminal. Bogotá: Temis.

Mittermaier, C. (2004). Tratado de la prueba en materia criminal: exposición comparada de los principios en materia criminal y de sus diversas aplicaciones en Francia, Inglaterra, etc. Madrid: Edit. Reus.

Montero, J. (1999). La intervención de las comunicaciones telefónicas en el proceso penal: (un estudio jurisprudencial). Valencia: Tirant lo Blanch, pp. 131-181-188.

Montañés, M. (1999). La intervención de las comunicaciones. Pamplona: Aranzadi.

Montoya, M. (2001a). El agente encubierto en la lucha contra el crimen organizado en la Argentina. Revista de Derecho Penal, Procesal Penal y Criminología, Mendoza, volumen 1, Fascículo 2, pp. 299-424.

Montoya, M. (2001b). Informantes y técnicas de investigación encubiertas. Análisis Constitucional y Procesal Penal. Buenos Aires: AD-HOC.

Muñoz, F. (2003). La búsqueda de la verdad en el proceso penal. Buenos Aires: Hammurabi.

Novoa, E. (1979). Derecho a la vida privada $y$ libertad de información México: Siglo XXI.

Pascua, F. (2003). Escuchas telefónicas, grabaciones de audio subrepticias $y$ filmaciones. Argentina: Edit. Jurídicas Cuyo, pp. 77-93-95-96-97-98-106-107-114-133. 
Rodríguez Lainz, J. L. (2002). La intervención de las comunicaciones telefónicas: su evolución en la jurisprudencia del Tribunal Constitucional y del Tribunal Supremo. Barcelona, España: Boch.

Roxin, C. (2000). Derecho procesal penal. Buenos Aires: Editores del Puerto.

Ruiz, E. (1997). El derecho penal sustantivo y el proceso penal: garantías constitucionales básicas en la realización de la justicia. Madrid: Ed. Colex.
Salgado, J. (2001). La utilización como medio de prueba de la intervención de las comunicaciones telefónicas, postales, telegráficas, informáticas y de las nuevas tecnologías de la comunicación. Conferencia $C I C A D$, Antigua-Guatemala.

Zamorano, A. (2006). Las pruebas obtenidas mediante las grabaciones sonoras y de imagen y las intervenciones telefónicas: su valor probatorio. Panamá. Conferencia pronunciada en el III Congreso Colombo-Panameño de Derecho Procesal. 